\title{
Application and Practice of Behavior-oriented Teaching Method in Accounting Teaching
}

\author{
Lian Jing \\ Shaanxi Technical College of Finance and Economics, Shaanxi, China, 712000
}

Keywords: Behavior-oriented Teaching method; accounting teaching; application; practice

\begin{abstract}
With the new orientation of today's outlook on education and talent, the predicament of traditional teaching methods is becoming more and more obvious. The accounting teaching digests and absorbs the basic principles of Western Behavior-oriented Teaching method, and tries to practice several typical teaching methods, which have achieved good teaching results. Finally, some experiences and reflections are discussed, and some directional suggestions are put forward for vocational schools to improve the effectiveness of professional teaching.
\end{abstract}

Modern society requires people to have three abilities (professional ability, social ability and methodological ability). Therefore, teachers should improve traditional teaching methods to meet the needs of demonstrability development. Therefore, through learning, introducing the Western Behavior-oriented Teaching Method and applying it in accounting teaching, we have achieved certain results.

\section{Definition of behavior-oriented teaching method}

Since the 1980s, Behavior-oriented Teaching method has gradually become a new trend of thought in Vocational Education teaching, which has been praised by experts in vocational education and labor circles all over the world. Behavior-oriented teaching method is a kind of teaching method in which students learn with their brain, heart and hands at the same time. This kind of teaching method is activity-oriented and ability-based. Through the guidance of behavior, students can improve their interest in learning, cultivate innovative thinking and form key abilities in activities.

\section{Basic Characteristics of Behavior-oriented Teaching Method}

Table 1. Basic Characteristics of Behavior-oriented Teaching Method

\begin{tabular}{|c|}
\hline Student Mutual Assistance and Cooperation to Solve Practical Problems \\
\hline Students participate in the whole teaching process together \\
\hline Students show strong desire for knowledge \\
\hline Fundamental changes in bleacher
\end{tabular}


As shown in Table 1, a detailed analysis is presented below.

\subsection{Student Mutual Assistance and Cooperation to Solve Practical Problems}

All the problems that need to be solved by students should be jointly participated in, discussed and assumed different roles, so that the problems can be solved in the process of mutual cooperation. The process of solving problems is also the process of learning and gaining experience.

\subsection{Students participate in the whole teaching process together}

From the collection of information, the formulation of plans, the selection of schemes, the implementation of objectives, the feedback of information to the evaluation of results, students participate in the whole process of problem solving. In this way, students not only understand the overall, but also the details of each specific link.

\subsection{Students show strong desire for knowledge}

Studentship desire for knowledge is due to active participation. On the one hand, students are intrinsically motivated by curiosity, interest and thirst for knowledge; on the other hand, they are externally encouraged by teachers and cooperated among students to make students happy after achieving results.

\subsection{Fundamental changes in bleacher}

Teachers change from knowledge and skills impartial to counseling guides, from actors to directors in the teaching process, but it does not affect the role of teachers. On the contrary, teachers are more demanding.

\section{The implementation of behavior-oriented teaching method in accounting teaching}

Accounting is the main course of Accounting Specialty in secondary vocational schools planned by the state, and it is also the basic course of Finance and economics specialty. How well students master this course will directly affect the study of other follow-up courses in their major, and also affect their future practice and work. The introduction part of the course at the beginning shows a strong professionalism, if taught in a conventional way, it will often make beginners daunted. Especially for some students with weak learning foundation, professional "opening remarks" can easily make them lose interest and confidence. Even if the teacher's explanation is correct in class, it will inevitably make the students drowsy.

Based on this understanding, the author conscientiously assimilates and absorbs modern educational theory, and closely adheres to the conditions of study, life and school, introducing Behavior-oriented Teaching Method into accounting classroom teaching. This teaching method mainly includes media use technology, graphic thinking, card display, project teaching method, brainstorming method, cooperative learning method, case analysis method, guiding text method, role playing method, simulation teaching method, etc.

\subsection{Media Use Technology}

Accounting course should gradually use modern information technology and multimedia technology to teach. Teachers can make their own teaching courseware to express the content of the course in an image and intuitive form, to popularize profound theories, to visualize Abstract 
problems, to simplify complex problems, and to facilitate misunderstanding and mastery. Computer multimedia can integrate words, pictures, images and sounds, bring students into the image, vivid and colorful teaching situation, so that extrasensory organs can be stimulated, while developing their left and right brains, developing their thinking ability, expanding students' spatial concepts, improving their perceptual understanding, deepening their understanding of things, greatly reducing the difficulty of misunderstanding, and becoming easier.

At the same time, using computer to process teaching materials can not only improve constitutionality and stimulate their thirst for knowledge, but also help to disperse difficulties and facilitate students' comparative analysis. For example, the filling of accounting vouchers, if the traditional blackboard teaching is time-consuming and laborious, can not achieve a clear effect; and the use of courseware broadcast teaching, not only visual image, but also can understand the specific method of filling in accounting vouchers, the teaching effect is much better. At the same time, the campus network can also be set up to run the teaching resources such as syllabus, teaching plan, exercises, courseware, experimental guidance and reference documents on the Internet, so as to facilitate studentship-access and active learning.

\subsection{Role Playing}

In classroom teaching, secondary vocational school students are allowed to play the role of enterprise accounting, and the economic practice is designed as a practical business decision-making problem. Please think, analyze and make decisions by "accounting". Emphasizing that there are no "students" in the classroom, only competent "accountants" who seek the best interests of enterprises can guide students to enter the role of economic practice and comprehend accounting knowledge. At the same time, to enhance studentship can also change the bad habits of many secondary vocational students who regard learning as a task.

\subsection{Constitutional Teaching Method}

Setting up situations according to existentialist knowledge, bringing students into roles, guiding students to actively participate in the teaching process, thinking and solving problems, so as to achieve learning objectives. For example, before teaching the concept of "assets", the author first gave the students such a daily example: "We now have 500,000 yuan, the annual interest rate deposited in the bank is $3 \%$, the annual rate of return for starting a printing plant is $30 \%$. We usually choose the latter scheme, and what do we need to start a printing plant? Let the students speak freely and express their opinions: "We need funds, factories, machinery and equipment, raw materials and so on." "Capital, bank deposits, factory buildings, machinery and equipment, raw materials are assets." Teachers and students then sum up the concept of assets together: "Assets are economic resources owned or controlled by enterprises and can be measured in monetary terms." Finally, on the basis of interdisciplinary understanding of the concept, students will be more easily understood and interested in learning.

\subsection{Visiting Method}

It is difficult for students to teach some contents of accounting course without perceptual knowledge. Therefore, it is better to provide students with sufficient time before class, take them to enterprises and the front line of accounting work before class, so as to enhance studentship feelings, so as to change the way of talking about soldiers blindly on paper and mobilize their enthusiasm for learning. For example, in order to make students better understand the business content of enterprise production products, students can first visit the teaching practice points - food factories, wine 
factories, understand the production process of products, and then summarize the business of the production process of products in the enterprise. Students are very impressed by the business of this process. At the same time, we can understand the setting up of accounting institutions in actual units and the information of tools, vouchers, books, statements and so on. We can also observe the accounting processing procedures in actual units, enhance perceptual understanding of accounting work, and enhance students' interest in learning this major.

\subsection{Project Teaching Method}

Project teaching method can be used in the teaching of filling out and auditing original accounting vouchers.

Firstly, a simulation environment is designed and a simulation company is established. As shown in Table 2.

Table 2.Simulation case

\begin{tabular}{|l|l|}
\hline Enterprise Name & Chongqing Limited Liability Company \\
\hline Address & No. 25 Municipal People's Road \\
\hline Enterprise Type & \multicolumn{1}{|c|}{ Limited Liability Company } \\
\hline Account Bank & $\begin{array}{l}\text { Cheongsam Branch of Industrial and Commercial Bank of } \\
\text { China.account number: 56002358 }\end{array}$ \\
\hline Main Products & A and B products \\
\hline $\begin{array}{l}\text { Accounting } \\
\text { method }\end{array}$ & debit and credit accounting method \\
\hline $\begin{array}{l}\text { Material pricing } \\
\text { method }\end{array}$ & pricing according to planned cost \\
\hline Director & Li Gingham \\
\hline
\end{tabular}

Secondly, the establishment of simulated accounting practice work situation. Establish a project teaching classroom which integrates theory teaching with transcendentalist and discussion. As Mr. Tao Xingu said, "Teachers and students are doing school, teaching, discussing and questioning." Really achieve the unity of teaching and doing. The whole process of practical training centers around three centers, namely, student-centered, project-centered and scenario-centered. It pays attention to the improvement of professional, social and methodological abilities, so as to truly form the professional judgment ability of accounting practice.

First Finance Department A student asked: If the seller receives a check drawn by the purchasing unit, how to deal with it when depositing the money in the bank for transfer? Teachers strongly praise the clues to the query and answer: endorse the cheque on the back, that is, stamp it. According to the plan, members can complete their tasks by searching for information, learning and practicing the filling of various types of original vouchers through various channels. Teachers watch and answer questions, advocate questioning, and patiently guide students to complete reflective notes.

\section{Conclusion}

Behavior-oriented teaching method is a new teaching method and a major breakthrough in the curriculum reform of Vocational education. Now, the Behavior-oriented Teaching method has initially shown its unique charm in accounting teaching. Uninteresting in learning has been greatly stimulated. The classroom atmosphere has become active, active and harmonious. Teachers' enthusiasm for teaching has increased. Semiprofessional ability, social ability, personality ability 
and methodological ability have also been constantly improved. The author firmly believes that with the further practice of this new teaching method, the teaching and research group will benefit more students.

\section{References}

[1] Ma Qingdao. New Views on Contemporary Vocational Education [M]. Shanghai: Shanghai Education Press, 2002

[2] Ye Chang yuan, Deng Nanjing. Behavior-oriented teaching method [M]. Hangzhou: Technical Teaching and Research Department, Shijiazhuang Labor and Social Security Department, 2001

[3] Tao Xingu's anthology [M]. Beijing: Commercial Press, 1994

[4] Li Olivia. Exploration and Practice of Teaching Reform of Basic Accounting [J]. China Science and Technology Information, 2006 (20): 240-241

[5] Bhang Usenet. Basic Accounting [M].3 Edition. Beijing: Higher Education Press, 2008 